\title{
Why we miss fetal growth restriction: Identification of \\ risk factors for severely growth restricted fetuses \\ remaining undelivered by 40 weeks' gestation.
}

\section{Miss Prerna DIKSHA ${ }^{1}$}

BBmed

Final Year Medical Student, University of Melbourne

Email: prerna.diksha@gmail.com

Professor Michael PERMEZEL ${ }^{1,2}$

FRANZCOG, MD, MBBS

Professor of Obstetrics and Gynaecology, University of Melbourne

Email: m.permezel@unimelb.edu.au

Doctor Natasha PRITCHARD ${ }^{1,2}$

MBBS, MRMed

Level 1 Trainee, The Royal Australian New Zealand College of Obstetricians and

Gynaecologists

Email: natasha.pritchard@trainee.ranzcog.edu.au

Address: 163 Studley Road, HEIDELBERG 3081

Phone: 0384587777

\section{Institutional Affiliations:}

${ }^{1}$ Faculty of Medicine, University of Melbourne, Parkville, Victoria, Australia

${ }^{2}$ Department of Obstetrics and Gynaecology, Mercy Hospital for Women,

Heidelberg, Victoria, Australia

\section{Financial disclosures:}

No author has any relevant financial disclosures.

\section{Acknowledgements:}

This is the author manuscript accepted for publication and has undergone full peer review but has not been through the copyediting, typesetting, pagination and proofreading process, which may lead to differences between this version and the Version of Record. Please cite this article as doi: $10.1111 /$ ajo.12818

This article is protected by copyright. All rights reserved 
The authors would like to thank the Mercy Hospital for Women's Medical Records Department, particularly Ms Justyna Bylinska and Ms Tania Fletcher, for their assistance with data collection

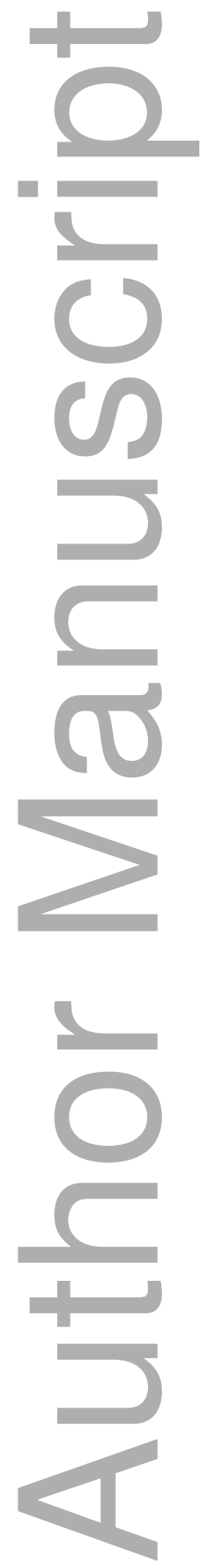


DR. NATASHA PRITCHARD (Orcid ID : 0000-0002-7388-2193)

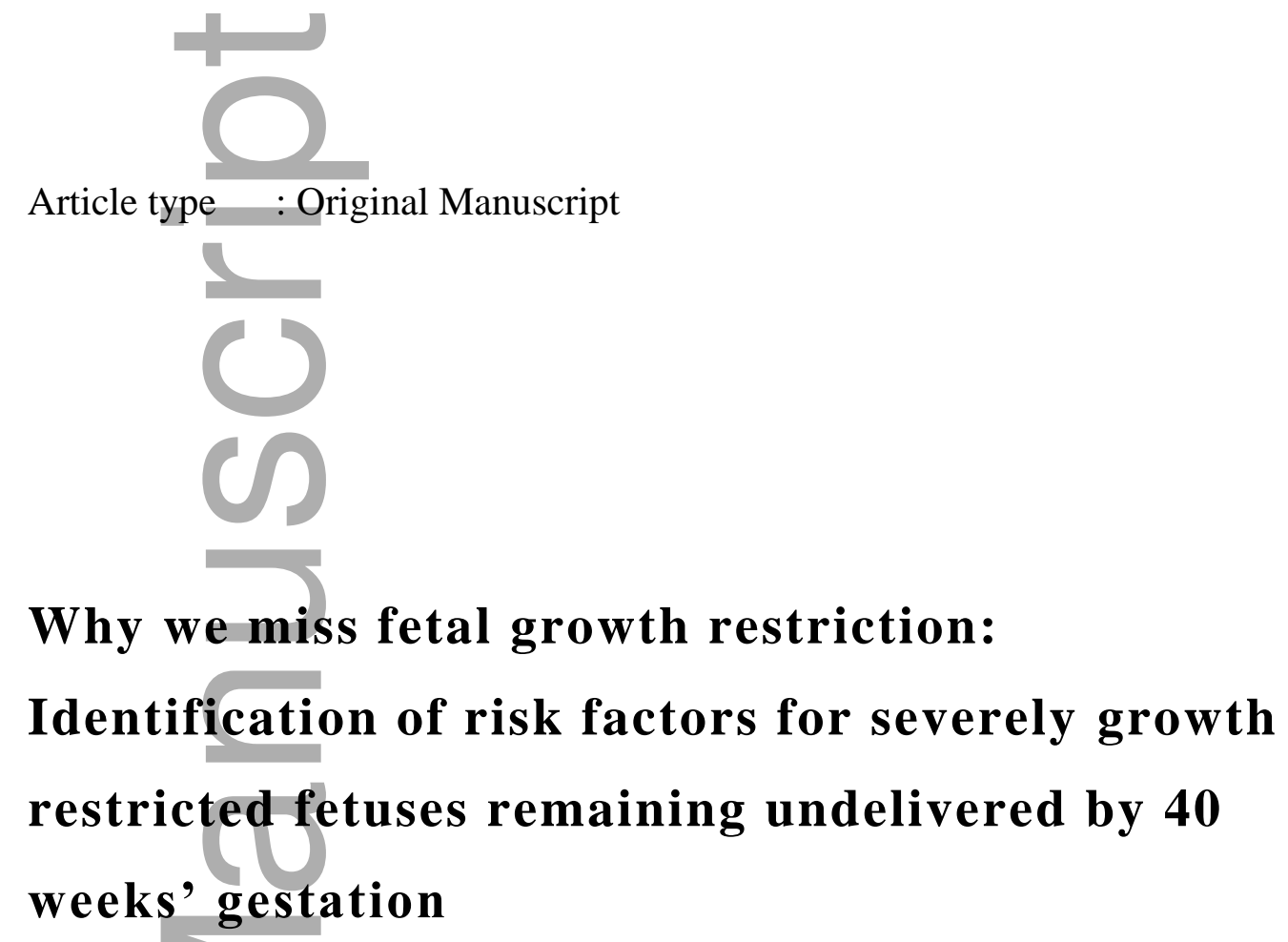

Short Title: Identification of risk factors for severe FGR.

Word Count (Abstract): 250

Word Count (Main Text): 2690

Tables and Figures Count: 4

Keywords:

Fetal Growth Restriction

Intrauterine Growth Restriction

Prenatal Ultrasonography

Fetal Biometry

Organisational Models 


\section{Abstract}

\section{BACKGROUND}

Severe fetal growth restriction (FGR) is a leading cause of adverse perinatal morbidity and mortality, however in Victoria, 35\% of severely growth-restricted infants are undelivered by 40 weeks' gestation.

\section{AIMS}

We aimed to identify factors associated with failure to deliver severely growth-restricted fetuses by 40 weeks' gestation.

\section{METHODS}

We conducted a retrospective case-control study of term singletons born $<3^{\text {rd }}$ centile for gestation at a single tertiary centre (2010-2017). Infants with a planned delivery for FGR between 37.0-39.6 weeks' gestation (“planned birth" group; $\mathrm{n}=187$ ) were compared with those undelivered by 40.0 weeks' ("undelivered" group; $n=233$ ). Variables assessed included the presence of risk factors for FGR, model of care, symphyseal-fundal height measurements and third-trimester ultrasounds.

\section{RESULTS}

An equivalent proportion of women were 'high-risk' for FGR on history (31.3\%vs38.0\%, $\mathrm{p}=0.187$ ) in the planned and undelivered groups. Women booked under low-risk models (shared care and midwifery-led care) were significantly more likely to be in the undelivered group compared to those booked under traditional collaborative models (79.8\%vs.37.4\%, $\mathrm{p}<0.001)$. Women in the undelivered group were less likely to have received a third-trimester ultrasound $(93.0 \%$ vs40.3\%, $\mathrm{p}<0.001)$, however were more likely to have had a reassuring ultrasound with an EFW or AC $>10^{\text {th }}$ centile $(78.7 \%$ vs. $16.1 \%, \mathrm{p}<0.001)$.

\section{CONCLUSIONS}

Failure to deliver the severely growth-restricted fetus before 40.0 weeks' is more likely to occur in the following situations: 1) failure to receive an indicated third-trimester ultrasound; 2) the presence of falsely reassuring third-trimester ultrasound scan; and 3) booking under a low-risk rather than traditional collaborative models of care. 


\section{Introduction}

Fetal growth restriction (FGR) is the pathological failure of a fetus to reach its biologically determined growth potential. ${ }^{1}$ Antenatal detection of FGR is a critical objective of maternity care, given that it is a significant cause of perinatal morbidity and mortality, and the single largest cause of unexplained stillbirth. ${ }^{2-4}$ Previous studies have demonstrated a seven-fold increase in adverse neonatal outcomes in fetuses with birthweight $<3^{\text {rd }}$ centile for gestational age. ${ }^{5}$ Complications include short-term neonatal morbidity such as intraventricular haemorrhage, necrotising enterocolitis and sepsis. ${ }^{67}$ Long-term sequelae include increased risk of cerebral palsy, cardiovascular and cerebrovascular disease, metabolic syndrome, type 2 diabetes mellitus and mental illness. ${ }^{8-10}$

Antenatal diagnosis of FGR has undeniable benefits. Intensive fetal surveillance (both antenatal and intrapartum) together with optimising timing of birth may reduce adverse perinatal outcomes by up to four-fold. ${ }^{11-13}$ However, the antenatal detection of FGR remains extremely challenging. Universal third-trimester ultrasound has been shown to detect less than two-thirds of growth-restricted infants, with even lower detection rates if relying on clinical suspicion alone. ${ }^{14}$

Given that adverse outcomes of FGR are known to rapidly increase with advancing gestation, ${ }^{15}$ the Victorian Department of Health has nominated 'severe intra-uterine growth restriction in a singleton pregnancy undelivered by 40 weeks' as a key performance indicator in the assessment of maternity care quality. However, during 2015-2016, over one-third of fetuses $<3^{\text {rd }}$ centile born in Victorian public hospitals remained undelivered at 40 weeks'. ${ }^{16}$ The performance indicator only includes infants born $<3^{\text {rd }}$ centile, as this group is less likely to be constitutionally small, and less reasonably undelivered, than the small-for-gestationalage (SGA) fetus between the $3^{\text {rd }}$ and $10^{\text {th }}$ centiles.

We aimed to identify which factors were associated with fetuses $<3^{\text {rd }}$ centile for birthweight being undelivered by 40 weeks' gestation, with a view to develop strategies to reduce the adverse consequences of undiagnosed severe FGR. 


\section{Methods}

\section{Study Population}

We conducted a retrospective case-control study at a single tertiary maternity centre in Victoria, the Mercy Hospital for Women (MHW), comparing those pregnancies in which severe FGR was diagnosed antenatally and delivered prior to 40 weeks' gestation, with severely growth-restricted infants undelivered by that time. Data was collected over a sevenyear period, from 1 March 2010 to 28 February 2017. Severe FGR was defined as $<3^{\text {rd }}$ centile for gestation and gender, using Australian population birthweight centiles for singleton infants (Dobbins, 2012) ${ }^{17}$ which are those currently used in the Victorian Perinatal Services Performance Indicators.

All singleton infants born $<3^{\text {rd }}$ centile at 40.0 weeks' gestation or later were identified as the cases ('undelivered' group). Controls were defined as singleton, term, infants $<3$ rd centile intentionally delivered by planned caesarean section or induction of labour, between $37.0-$ 39.6 weeks' gestation, with a documented indication for delivery being suspected placental insufficiency ('planned birth' group). Women who underwent spontaneous labour prior to 40.0 weeks' gestation were excluded, as it was uncertain whether a conscious decision to deliver based on suspected fetal growth restriction would have occurred or not. Women who had an elective caesarean section or induction prior to 40.0 weeks' gestation were also excluded, if growth restriction or suspected placental insufficiency was not documented as a reason for delivery, as delivery timing may have been unrelated to the discovery of growth restriction.

Multiple pregnancies and congenital fetal anomalies (major structural malformations, major chromosomal or metabolic disorders) were excluded. Women with no first-trimester ultrasound were excluded, to ensure all had an accurately dated pregnancy.

\section{Data Source}

Cases and controls were identified using the Birthing Outcomes System (BOS), a database in which midwives record patient characteristics, delivery indications and birthing outcomes as part of routine maternity care. Individual medical records were used to obtain medical, obstetric and antenatal history and to determine model of care. Information about antenatal appointments and continuity of care was checked against the Inpatient Management (IPM) system, which contains an electronic catalogue of each maternity visit at the hospital by 
patients. Ultrasound reports were obtained from Clinical Patient Folder (CPF), a system recording all clinical investigations.

\section{Outcome Measures}

\section{(i) Baseline Characteristics and Risk Factors for FGR on History}

Baseline characteristics assessed included maternal age, body mass index (BMI), height, parity, gestational age at delivery and mode of conception. Known risk factors for FGR were documented, including previous SGA infants $<10^{\text {th }}$ centile or $<3^{\text {rd }}$ centile, previous stillbirth, pregnancy interval $<6$ or $>60$ months, pregnancy-associated plasma A protein (PAPP-A) $<0.4$ MoM, pre-eclampsia, gestational hypertension, gestational diabetes mellitus and smoking, alcohol or illicit drug use during pregnancy. Medical conditions were recorded including essential hypertension, pre-existing diabetes mellitus, autoimmune disease (systemic lupus erythematosus, antiphospholipid syndrome), thrombophilias, cardiovascular disease, chronic pulmonary disease, renal insufficiency, congenital infections, iron deficiency anaemia and thalassaemia. Risk factors were considered to be 'major' or 'minor' in accordance with international obstetric guidelines. ${ }^{18}$ We defined women as 'high-risk' for FGR if they had at least 3 minor risk factors, or 1 major risk factor. ${ }^{18}$

\section{(ii) Models of Care}

Four major maternity models of care were identified at the MHW, which align with national and international antenatal care structures; ${ }^{19-21}$ general practitioner (GP) shared care, midwife-led care, traditional collaborative care by public obstetricians and midwives, and care by a private obstetrician. In accordance with Victorian maternity care frameworks, ${ }^{22} \mathrm{GP}$ shared care and midwife-led care were grouped as 'low-risk' models. Traditional collaborative care and private obstetric care were grouped as 'mixed-risk' models, as they cared for both low and high-risk patients.

The model of care the woman was allocated to at her first antenatal booking visit, as well as the predominant model of care in the third-trimester (beyond 28 weeks') was recorded. If the woman was transferred from a low-risk to a mixed-risk model, this was noted. Continuity of care was defined as seeing the same type of health professional (either midwives, GPs or obstetricians) or the same individual health professional (exact same midwife, GP or obstetrician), over at least three of the five consecutive visits prior to birth and prior to 39 weeks'. 


\section{(iii) Symphyseal Fundal Height (SFH) Measurements}

The last three SFH measurements prior to birth, and prior to 39 weeks' gestation, were recorded. We assessed whether the fundal height had been measuring significantly behind dates or remained static. The former was defined as a SFH of at least $3 \mathrm{~cm}$ less than the current gestational age and the latter as no growth in SFH over two or more consecutive measurements, with at least a two-week gap between the visits.

\section{(iv) Third-Trimester Ultrasound}

We assessed whether third-trimester ultrasound biometry was performed and the mean number of scans performed if one was conducted. As per international guidelines, one major risk factor or three minor risk factors were considered indications for a third-trimester ultrasound. ${ }^{18}$ Ultrasound estimations of fetal weight (EFW) and abdominal circumference (AC) were separately assessed with respect to: $<10^{\text {th }}$ centile, $<25^{\text {th }}$ centile or 'slowed growth' (centile decreasing by $\geq 25$ centiles).

\section{Statistical Analysis}

Means, standard deviations, medians or percentages of the total were used to describe outcomes of interest. Chi-squared tests were used for analysis of categorical variables, and the unpaired Student's t-test for analysis of continuous variables that approximated a normal distribution. Statistical significance was regarded as a p-value $<0.05$. Statistical analysis was performed using GraphPad Prism Version 7.0c, 2017.

\section{Ethics}

Ethics approval was granted by the Human Research Ethics Committee at the Mercy Hospital for Women (approval project number R16:18).

\section{Results}

Over the 7-year period, 466 infants were identified who met the inclusion criteria. Of these, 46 were excluded, due to an inaccurately dated pregnancy $(n=25)$, no antenatal record available ( $n=14)$, fetal malformation $(n=6)$ and multiple pregnancy $(n=1)$; leaving 420 available for analysis. Additionally, patients under shared care $(n=36)$ or private care $(n=35)$ at booking visit were excluded from the analysis of continuity of care and SFH measurement, due to incomplete information in their histories.

\section{Baseline Characteristics}


Maternal age, parity, height, BMI and mode of conception were equivalent in the planned birth and undelivered groups (Table 1). As expected, the mean gestational age at delivery was greater in the undelivered group (40.6 weeks') compared to the planned birth group (38.3 weeks'), demonstrating a significantly earlier gestation at delivery if FGR was detected.

\section{Risk Factors on Maternal History}

Overall, an equivalent number of women in both groups were considered high-risk based on medical or obstetric risk factors (Table II). Further, women were equally as likely to smoke, drink alcohol, or have had a previous SGA baby $<10^{\text {th }}$ centile. Women who used illicit substances during pregnancy were more likely to be in the planned birth group (11 (5.9\%) vs $2(0.9 \%)$ women, $\mathrm{p}=0.008)$. All women who had a low PAPP-A were in the planned birth group $(8(4.3 \%)$ vs $0(0 \%), \mathrm{p}=0.005)$.

\section{Models of Maternity Care}

Table III demonstrates that almost $80 \%$ of women undelivered by 40.0 weeks' were booked under low-risk models, compared with only $20 \%$ booked under mixed-risk models. However, women having a planned birth were much more likely to have been booked in a mixed-risk model $(117$ (62.6\%) vs $70(37.4 \%)$, p<0.001). If a woman was booked under lowrisk care, and did not spontaneously labour or get delivered for another reason, she had a $73 \%$ (186 of 256) chance of remaining undelivered by 40.0 weeks' gestation, compared with a $27 \%$ chance ( 47 of 164 ) of being undelivered if booked under collaborative models.

\section{Symphyseal Fundal Height Measurements}

Planned birth for FGR was strongly associated with a fundal height measuring below the expected gestation prior to birth on any of the last three measurements (126 of 167 (75.5\%) vs 61 of $179(34.1 \%), \mathrm{p}<0.001)$ and on the most recent measurement (110 of $167(65.9 \%)$ vs 47 of $179(26.3 \%), \mathrm{p}<0.0001)$; and with static fundal growth on any of the last three measurements (53 of 167 (31.7\%) vs 26 of 179 (14.5\%), p<0.0001) (Table 4).

\section{Third-Trimester Ultrasound Scans}

Table 4 shows that receiving a third-trimester ultrasound was significantly associated with planned birth for FGR (174 (93.0\%) vs 94 (40.3\%), p<0.001). An equivalent proportion of women were high-risk for FGR and warranted a third-trimester ultrasound in both the cases and controls (73 (31.3\%) vs $71(38.0 \%)$ ). All women with an ultrasound indicated on history 
received one in the planned birth group, compared to approximately half of those delivering after 40.0 weeks' (71 of $71(100 \%)$ vs 38 of $73(52.1 \%), \mathrm{p}<0.001)$.

The presence of falsely reassuring fetal size on ultrasound was strongly associated with being in the undelivered group. Of the undelivered group, 78.7\% (74 of 94) were falsely reassured by an EFW or $\mathrm{AC}>10^{\text {th }}$ centile on all third-trimester ultrasounds, compared with only $16.1 \%$ (28 of 174) of those with a planned birth having all scans within normal limits $(\mathrm{p}<0.001)$. It is noteworthy that of those in the undelivered group that had a third-trimester ultrasound, $61.7 \%$ (58 of 94 ) had a fetus measuring $<25^{\text {th }}$ centile for EFW or AC on at least one scan $(\mathrm{p}<0.001)$. Of those women that had at least two ultrasounds, significantly more of undelivered group had ultrasound evidence of crossing growth centiles (15/ 39 (38.6\%) vs $12 / 116(10.3 \%), \mathrm{p}<0.001)$.

\section{Discussion}

Our study provides insights into the factors leading to severe FGR being undelivered by 40.0 weeks' gestation. We identified key factors that differed between women in whom birth was planned before 40.0 weeks' and those who were undelivered past 40.0 weeks'.

Approximately one third of women in the study were defined as high-risk for FGR on the basis of underlying risk factors. This proportion did not differ between the planned birth and undelivered groups. We had hypothesised initially that women with multiple risk factors for FGR would be more easily identified and thus less likely to be missed, however this was not the case. This can at least in part be explained by the presence of risk factors failing to trigger an indicated third-trimester ultrasound in almost $50 \%$ of women in whom a scan was indicated.

Two risk factors were independently associated with detection of FGR; low PAPP-A and use of illicit substances during pregnancy. At the study centre, a specific guideline for women with PAPP-A <0.4 MOM recommends a third-trimester ultrasound. This contrasts with other obstetric or medical risk factors that frequently failed to trigger an indicated scan, and may reflect the importance of a local guideline endorsed by the hospital's obstetricians and midwives. Women using illicit substances are cared for in a dedicated high-risk unit that includes heightened fetal surveillance and a low threshold for delivery before 40 weeks' gestation. 
A low-risk model of maternity care was strongly associated with an increased likelihood of being in the undelivered group. This was true for both the model of care at booking, and also the model of care during the third-trimester. Importantly, this was irrespective of the presence or absence of underlying risk factors. The relative absence of third-trimester ultrasounds in the undelivered group suggests that a very small baby was not suspected.

Previous studies, including two small Australian randomised controlled trials (RCTs) and a Cochrane review, ${ }^{23-26}$ found no differences in serious perinatal outcomes between midwiferyled models compared to conventional collaborative models. However, serious adverse obstetric outcomes are so infrequent that small but important differences will seldom be demonstrable using RCT methodology. Severe FGR is strongly associated with stillbirth but is much more frequent, and this may be why we have detected differences not seen in other studies.

As anticipated, those with planned birth for FGR were more likely to have had reduced or static symphyseal-fundal height measurements identified. It may be that healthcare providers in collaborative-care models see FGR more frequently and have a higher index of suspicion.

Also as expected, those women who received a third-trimester ultrasound were significantly more likely to be in the planned birth group. Moreover, if an ultrasound was indicated based on history, every woman in the planned birth group received it, compared to only half of women in the undelivered group. These findings provide compelling arguments for the need for clear guidelines stipulating the indications for performing third-trimester growth scans.

Finally, we observed that of those women who had a third-trimester ultrasound and had a planned birth, the vast majority had at least one scan with EFW or AC $\leq 10^{\text {th }}$ centile. Conversely, only one in five of those of women in the undelivered group had an ultrasound with $\mathrm{EFW}$ or $\mathrm{AC} \leq 10^{\text {th }}$ centile, although almost two-thirds had a fetus measuring $\leq 25^{\text {th }}$ centile for EFW or AC on ultrasound. Given the margin of error inherent in ultrasound, it is important to maintain a high level of clinical suspicion for FGR among the subpopulation that are close to, but not less than, the $10^{\text {th }}$ centile. As FGR at term can be the result of lateonset pathology, it is also important not to be falsely reassured by ultrasounds performed early in the third-trimester, as they may not be representative of later fetal size. Those in the undelivered group were more likely to have crossed centiles on ultrasound, indicating slowing of growth while still remaining within normal parameters in their most recent 
ultrasound. This demonstrates that decelerating fetal growth is an area necessitating stronger clinical suspicion and consideration for delivery.

\section{Strengths and Limitations of Study}

We believe our findings make a significant contribution to the literature as we are not aware of any studies of severely growth restricted $\left(<3^{\text {rd }}\right.$ centile $)$ term singletons, that have compared those born by planned birth with those going up to or beyond their due date. Our study incorporates a large sample size, in a single centre, representative of contemporary obstetric practice. An inherent limitation of the study is its retrospective design. To ensure accuracy of our records, we used multiple data sources, including paper medical histories and three electronic databases. However, some information was difficult to obtain, including symphyseal height and ultrasound data from the history of women in shared or private care. We were also unable to take into consideration the role of maternal choice in the timing of delivery. If is possible that women who seek out low-risk models of care may also be those less inclined to accept interventions by induction or caesarean section even in the event of an identified small fetus, and that there is a proportion of women in whom early delivery was offered and declined.

\section{Conclusions}

Severe FGR is an area of national public health significance associated with such perinatal morbidity and mortality that birth of the infant $<3^{\text {rd }}$ centile at or after 40.0 weeks' has been adopted by the Victorian Department of Health as a maternity care performance indicator. We identified key differences in the care that the severely growth restricted $\left(<3^{\text {rd }}\right.$ centile), term singleton fetus with planned birth before 40.0 weeks' received compared to those undelivered at or beyond 40.0 weeks'. Women were much more likely to have been cared for under 'low-risk' models in the undelivered group, irrespective of the woman's underlying risk factors for FGR. This provides a strong argument for education and up-skilling of lowrisk carers, as they are an essential part of our maternity workforce. Women were also much less likely to have had a third-trimester ultrasound in the undelivered group; even if clinically indicated. If an ultrasound was performed, it was more likely to be falsely reassuring. Our findings identify targetable areas for improvements in maternity care in the hospital. 


\section{References}

1. Unterscheider J, Daly S, Geary MP, et al. Optimizing the definition of intrauterine growth restriction: the multicenter prospective PORTO Study. Am J Obstet Gynecol. 2013;208(4):290.e1-6.

2. Gardosi J, Madurasinghe V, Williams M, et al. Maternal and fetal risk factors for stillbirth: population based study. BMJ. 2013;346:f108.

3. Sameshima H, Ikenoue T, Miyazaki Perinatal Data Group. Risk factors for perinatal deaths in Southern Japan: population-based analysis from 1998 to 2005. Early Hum Dev. 2008;84(5):319-23.

4. Hirst JE, Villar J, Victora CG, et al. The antepartum stillbirth syndrome: risk factors and pregnancy conditions identified from the INTERGROWTH-21st Project. BJOG. 2016. DOI; 10.1111/1471-0528.14463.

5. Lindqvist PG, Molin J. Does antenatal identification of small-for-gestational age fetuses significantly improve their outcome? Ultrasound Obstet Gynecol. 2005;25(3):258-64. 6. Mendez-Figueroa H, Truong VT, Pedroza C, et al. Small-for-gestational-age infants among uncomplicated pregnancies at term: a secondary analysis of 9 Maternal-Fetal Medicine Units Network studies. Am J Obstet Gynecol. 2016;215(5):628.e1-.e7.

7. Chauhan SP, Beydoun H, Chang E, et al. Prenatal detection of fetal growth restriction in newborns classified as small for gestational age: correlates and risk of neonatal morbidity. Am J Perinatol. 2014;31(3):187-94.

8. Pallotto EK, Kilbride HW. Perinatal outcome and later implications of intrauterine growth restriction. Clin Obstet Gynecol. 2006;49(2):257-69.

9. Zubrick SR, Kurinczuk JJ, McDermott BM, et al. Fetal growth and subsequent mental health problems in children aged 4 to 13 years. Dev Med Child Neurol. 2000;42(1):14-20.

10. Barker DJ. Adult consequences of fetal growth restriction. Clin Obstet Gynecol. 2006;49(2):270-83.

11. Imdad A, Yakoob M, Siddiqui S, Bhutta Z. Screening and triage of intrauterine growth restriction (IUGR) in general population and high risk pregnancies: a systematic review with a focus on reduction of IUGR related stillbirths. BMC Public Health. 2011;11(Suppl 3):S1.

12. Seravalli V, Baschat AA. A uniform management approach to optimize outcome in fetal growth restriction. Obstet Gynecol Clin North Am. 2015;42(2):275-88. 
13. Figueras F, Gardosi J. Intrauterine growth restriction: new concepts in antenatal surveillance, diagnosis, and management. Am J Obstet Gynecol. 2011;204(4):288-300.

14. Sovio U, White IR, Dacey A, et al. Screening for fetal growth restriction with universal third trimester ultrasonography in nulliparous women in the Pregnancy Outcome Prediction (POP) study: a prospective cohort study. Lancet. 2015;386(10008):2089-97.

15. Crimmins S, Desai A, Block-Abraham D, et al. A comparison of Doppler and biophysical findings between liveborn and stillborn growth-restricted fetuses. Am J Obstet Gynecol. 2014;211(6):669.e1-10.

16. Department of Health and Human Services. Victorian perinatal services performance indicators: 2015-16. 1 Treasury Place, Melbourne: Governent of Victoria; 2017; 33-5.

17. Dobbins T, Sullivan E, Roberts C, Simpson J. Australian national birthweight percentiles by sex and gestational age, 1998-2007. MJA. 2012;197:291-4.

18. Royal College of Obstetricians and Gynaecologists. The investigation and management of the small-for-gestational-age fetus. Green-top Guideline. 2013;31(2).

19. Royal Australian and New Zealand College of Obstetricians and Gynaecologists. Maternal suitability for models of care, and indications for referral within and between models of care (C-Obs 30); 2015 [Cited 2017 August 20]. Available from: https://www.ranzeog.edu.au/Statements-Guidelines.

20. National Institute for Health and Clinical Excellence. Antenatal care: routine care for the healthy pregnant woman NICE Clinical Guideline CG6; 2008 [Cited 2017 April 6]. Available from: http://www.nice.org.uk/nicemedia/live/11947/40115/40115.pdf.

21. Posthumus AG, Scholmerich VL, Waelput AJ, et al. Bridging between professionals in perinatal care: towards shared care in the Netherlands. Matern Child Health J. 2013;17(10):1981-9.

22. Victorian Government Department of Health. Capability framework for Victorian maternity and newborn services. Melbourne. 2010.

23. Sandall J, Soltani H, Gates S, et al. Midwife-led continuity models versus other models of care for childbearing women. Cochrane Database Syst Rev. 2016(9):Cd004667.

24. Waldenstrom U, Turnbull D. A systematic review comparing continuity of midwifery care with standard maternity services. BJOG. 1998;105(11):1160-70.

25. Biró M, Waldenström U, Pannifex J. Team midwifery care in a tertiary level obstetric service: a randomized controlled trial. Birth. 2000;27(3):168-73.

26. Waldenström U, McLachlan H, Forster D, et al. Team midwife care: maternal and infant outcomes. Aust N Z J Obstet Gynaecol. 2001;41(3):257-64. 
Table I: Baseline Characteristics

\begin{tabular}{|cccc|}
\hline Characteristic & $\begin{array}{c}\text { Undelivered } \\
(\mathbf{n = 2 3 3})\end{array}$ & $\begin{array}{c}\text { Planned birth } \\
(\mathbf{n = 1 8 7})\end{array}$ & p-value \\
\hline Maternal age $(\mathrm{y})$ & $31.62(4.68)$ & $31.28(5.05)$ & 0.463 \\
Age 35-40(\%) & $44(18.9)$ & $42(22.5)$ & 0.435 \\
Age $>40(\%)$ & $10(4.3)$ & $3(1.6)$ & 0.195 \\
& & $38.3(0.73)$ & $<\mathbf{0 . 0 0 0 1}$ \\
\hline Gestation at delivery (weeks) & $40.6(0.55)$ & $119(63.6)$ & 0.120 \\
\hline Nulliparity (\%) & $166(71.2)$ & $159.1(6.10)$ & 0.369 \\
\hline Maternal height (cm) & $157.1(6.61)$ & $23.6(4.85)$ & 0.651 \\
\hline BMI (kg/m $\left.{ }^{2}\right)$ & $23.4(4.60)$ & $15(8.0)$ & 0.610 \\
BMI 30-35 (\%) & $22(9.4)$ & $7(3.7)$ & 0.687 \\
BMI $>35(\%)$ & $6(2.6)$ & $2(1.1)$ & 0.307 \\
\hline IVF conception (\%) & $7(3.0)$ & & \\
\hline $\begin{array}{l}\text { Continuous variables are summarised with mean (SD) and categorical variables with n (\%).BMI; body } \\
\text { mass index, IVF; in vitro fertilisation. }\end{array}$ & &
\end{tabular}

Table II: Association between risk factors on history and detection of fetal growth restriction.

\begin{tabular}{|c|c|c|c|}
\hline Outcome & $\begin{array}{l}\text { Undelivered } \\
(\mathrm{n}=\mathbf{2 3 3})(\%)\end{array}$ & $\begin{array}{l}\text { Planned birth } \\
(\mathrm{n}=187)(\%)\end{array}$ & P value \\
\hline \multicolumn{4}{|l|}{ Overall Risk Categorył } \\
\hline Low-Risk & $160 / 233(68.7)$ & $116 / 187(62.1)$ & 0.187 \\
\hline High-Risk & $73 / 233(31.3)$ & $71 / 187(38.0)$ & \\
\hline Medical Risk F actors & $28 / 233(12.0)$ & 20/187 (10.7) & 0.788 \\
\hline Essential hypertension & $3 / 233(1.29)$ & $0 / 187(0)$ & 0.33 \\
\hline Pre-existing diabetes mellitus & $0 / 233(0)$ & $0 / 187(0)$ & - \\
\hline Autoimmune disease & $2 / 233(0.86)$ & $2 / 187(1.07)$ & 0.776 \\
\hline Thrombophilias & $2 / 233(0.86)$ & $0 / 187(0)$ & 0.578 \\
\hline Othert & $7 / 233(3)$ & $14 / 187(7.49)$ & 0.062 \\
\hline
\end{tabular}




\begin{tabular}{|lccc|}
\hline Obstetric Risk Factors & & & \\
Previous SGA $<10^{\text {th }}$ centile & $35 / 67(52.2)$ & $41 / 68(60.3)$ & 0.441 \\
Previous FGR $<3^{\text {rd }}$ centile & $20 / 67(29.9)$ & $25 / 68(36.8)$ & 0.503 \\
Previous stillbirth & $2 / 67(1.5)$ & $2 / 68(2.9)$ & 0.99 \\
Pregnancy interval $<6$ or $>60$ months & $1 / 233(0.4)$ & $2 / 187(1.1)$ & 0.848 \\
Low PAPP-A <0.4 MoM & $0 / 233(0)$ & $8 / 187(4.3)$ & $\mathbf{0 . 0 0 5}$ \\
Preeclampsia/ gestational hypertension & $14 / 233(6.0)$ & $10 / 187(5.4)$ & 0.937 \\
Gestational diabetes mellitus & $14 / 233(6.0)$ & $16 / 187(8.6)$ & 0.414 \\
CMV or toxoplasmosis infection & $0 / 233(0)$ & $0 / 187(0)$ & - \\
Smoking & $24 / 233(10.3)$ & $22 / 187(11.8)$ & 0.749 \\
Alcohol consumption & $11 / 233(4.7)$ & $6 / 187(3.2)$ & 0.594 \\
Illicit substance use & $2 / 233(0.9)$ & $11 / 187(5.9)$ & $\mathbf{0 . 0 0 8}$ \\
\hline
\end{tabular}

†High risk; 3 minor or 1 major risk factors for FGR, low risk; 0-2 minor risk factors for FGR. $\neq$ Other:

Cardiac disease, chronic pulmonary disease, renal insufficiency, iron deficiency and thalassaemia

Table III: Association between models of maternity care and detection of fetal growth restriction.

\begin{tabular}{|cccc|}
\hline & $\begin{array}{c}\text { Undelivered } \\
(\mathrm{n}=233)(\%)\end{array}$ & $\begin{array}{c}\text { Planned birth } \\
(\mathrm{n}=187)(\%)\end{array}$ & p-value \\
\hline $\begin{array}{c}\text { Model of care at booking } \\
\text { Low-risk }\end{array}$ & $186(79.8)$ & $70(37.4)$ & $<0.001$ \\
Mixed-risk & $47(20.2)$ & $117(62.6)$ & \\
\hline $\begin{array}{c}\text { Model of care in third trimester } \\
\text { Low-risk } \\
\text { Mixed-risk }\end{array}$ & $163(69.6)$ & $49(26.2)$ & $<0.001$ \\
\hline
\end{tabular}

Table IV: Association between symphyseal fundal height, third-trimester ultrasound and detection of fetal growth restriction.

\begin{tabular}{|llll|}
\hline Outcome & $\begin{array}{c}\text { Undelivered } \\
(\mathbf{n = 2 3 3})(\boldsymbol{\%})\end{array}$ & $\begin{array}{c}\text { Planned birth } \\
(\mathbf{n = 1 8 7})(\boldsymbol{\%})\end{array}$ & P-value \\
\hline Symphyseal Fundal Height & & & \\
\hline Fundus < dates on last 3 measurements $\dagger$ & $61 / 179(34.1)$ & $126 / 167(75.5)$ & $<\mathbf{0 . 0 0 1}$ \\
\hline
\end{tabular}




\begin{tabular}{|lccc|}
\hline Fundus $<$ dates on most recent measurement & $47 / 179(26.3)$ & $110 / 167(65.9)$ & $<\mathbf{0 . 0 0 1}$ \\
\hline Static growth on last 3 measurements & $26 / 179(14.5)$ & $53 / 167(31.7)$ & $<\mathbf{0 . 0 0 1}$ \\
\hline Performance of Third- Trimester Ultrasound & & & \\
\hline Scan performed & $94 / 233(40.3)$ & $174 / 187(93.0)$ & $<\mathbf{0 . 0 0 1}$ \\
\hline Mean number of scans performed (SD) $\S$ & $1.6(0.82)$ & $2.5(1.32)$ & $<\mathbf{0 . 0 0 1}$ \\
\hline Mean gestation at first scan (weeks) (SD) & $33.2(3.14)$ & $32.4(3.47)$ & 0.0656 \\
\hline Mean gestation at most recent scan (weeks) & $35.2(2.27)$ & $36.3(1.51)$ & $<\mathbf{0 . 0 0 1}$ \\
\hline Scan performed if indicated on history & $38 / 73(52.1)$ & $71 / 71(100)$ & $<\mathbf{0 . 0 0 1}$ \\
\hline Third Trimester Ultrasound Parameters $\S$ & & & \\
\hline EFW or AC $\leq 10$ th centile on any scan & $20 / 94(21.3)$ & $146 / 174(83.9)$ & $<\mathbf{0 . 0 0 1}$ \\
\hline EFW or AC $\leq 25$ th centile on any scan & $58 / 94(61.7)$ & $156 / 174(89.7)$ & $<\mathbf{0 . 0 0 1}$ \\
\hline EFW orAC $\leq 10$ th centile on most recent scan & $15 / 94(16.0)$ & $134 / 174(77.1)$ & $<\mathbf{0 . 0 0 1}$ \\
\hline EFW or AC $\leq 25$ th centile on most recent scan & $53 / 94(56.4)$ & $144 / 174(82.8)$ & $<\mathbf{0 . 0 0 1}$ \\
\hline Crossing of growth centiles $\dagger \dagger$ & $15 / 39(38.6)$ & $12 / 116(10.3)$ & $<\mathbf{0 . 0 0 1}$ \\
\hline
\end{tabular}

$\dagger$ Fundus measuring at least $3 \mathrm{~cm}$ less than the expected equivalent gestation on any of the last $3 \mathrm{SFH}$ measurements prior to birth.\$ No growth in SFH over two or more consecutive measurements gestations, with at least a two-week gap between visits. $\$$ Out of those that received an ultrasound. $\dagger \dagger$ Fetus crossing $\geq 25$ centiles for EFW or AC on any two consecutive scan in the third trimester.

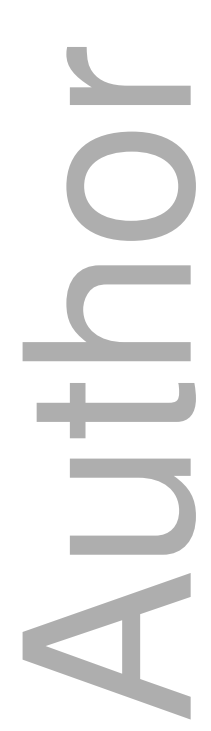

This article is protected by copyright. All rights reserved 


\section{University Library}

\section{- M M I N E R VA \\ A gateway to Melbourne's research publications}

Minerva Access is the Institutional Repository of The University of Melbourne

Author/s:

Diksha, P;Permezel, M;Pritchard, N

Title:

Why we miss fetal growth restriction: Identification of risk factors for severely growthrestricted fetuses remaining undelivered by 40 weeks gestation

Date:

2018-12-01

\section{Citation:}

Diksha, P., Permezel, M. \& Pritchard, N. (2018). Why we miss fetal growth restriction: Identification of risk factors for severely growth-restricted fetuses remaining undelivered by 40 weeks gestation. AUSTRALIAN \& NEW ZEALAND JOURNAL OF OBSTETRICS \& GYNAECOLOGY, 58 (6), pp.674-680. https://doi.org/10.1111/ajo.12818.

Persistent Link:

http://hdl.handle.net/11343/283899 